\title{
OPTIMIZATION AND VALIDATION OF A LIQUID CHROMATOGRAPHIC METHOD FOR DETERMINATION OF
} CAPSAICIN IN CHILI PEPPERS

\author{
JESSY PAVÓN-PÉREZ ${ }^{A}$, CARLOS PEÑA-FARFAL ${ }^{B}$, MARIO ARANDA ${ }^{A, C}$ AND KAREM HENRIQUEZ-AEDO*C,D \\ ${ }^{a}$ Laboratory of Advanced Research on Foods and Drugs, Department of Food Science and Technology, Faculty of Pharmacy, \\ University of Concepcion. \\ ${ }^{b}$ Department of Analytical and Inorganic Chemistry, Faculty of Chemistry Science, University of Concepcion. \\ c Center of Biotechnology, University of Concepcion. \\ ${ }^{d}$ Laboratory of Biotechnology and Food Genetic, Department of Food Science and Technology, Faculty of Pharmacy, University of \\ Concepcion
}

\section{ABSTRACT}

Capsaicinoids are organic compounds present in several foods like chili peppers. This group of molecules are responsible of fruit pungency, as well as, of several healthy properties. The present work reports an optimized and validated liquid chromatography method coupled to fluorescence and mass spectrometry detectors for a selective determination of capsaicin in Chili peppers (Capsicum annum and C. pendulum). To the best our knowledge this is the first report about capsaicin determination in chili peppers commercialized in Chile. Chromatographic conditions were optimized giving the following optimal conditions: $76 \%$ organic phase (MeOH: ACN: acetic acid (50:50:0.1 v/v/v) at 9 min of gradient program and column temperature of $35^{\circ} \mathrm{C}$. With these conditions capsaicin, dihydrocapsaicin and nordihydrocapsaicin were separated in 15 min. Data calibration curve $\left(0.01-2.00 \mathrm{mg} \mathrm{L}^{-1}\right)$ fitted a linear regression model with a determination coefficient $\left(R^{2}\right)$ of 0.9986. Repeatability (relative standard deviation, RSD) and intermediate precision (RSD) showed values of $1.51 \%$ ( $n=6)$ and $1.04 \%$ ( $n=3$ ), respectively. Recovery $(n=3)$ at three levels ranged from 94.80 to $109.40 \%$, (RDS $<2.39 \%$ ). The method was applied to analyze 10 chili peppers varieties commercialized in Chile. A broad range of capsaicin and dihydrocapsaicin contents were observed, finding values from 0.1 up to $127.3 \mu \mathrm{g} \mathrm{g}^{-1}$.

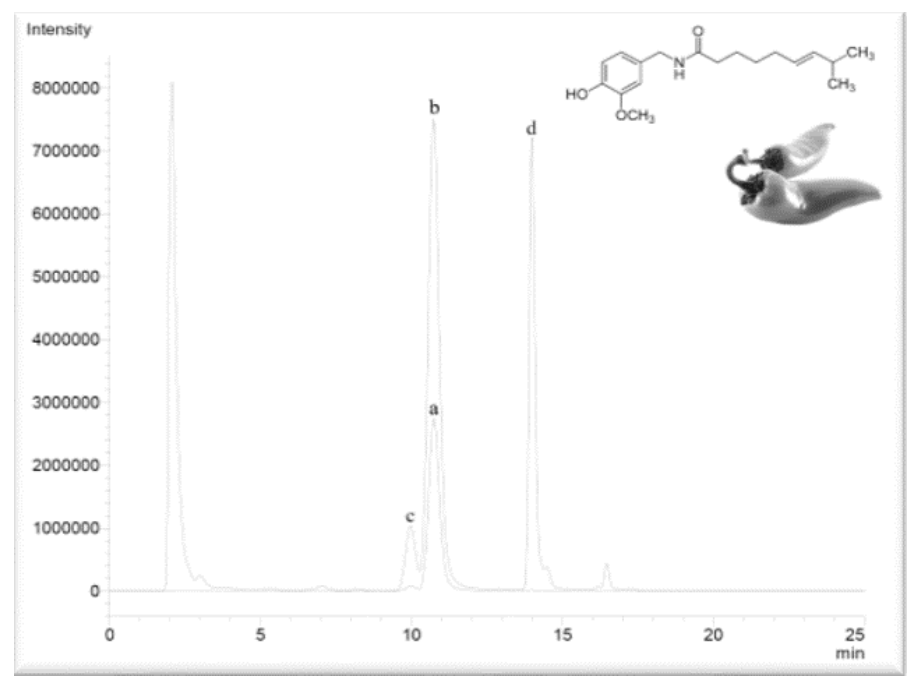

Keywords: Capsaicinoids, capsaicin, fluorescence, mass spectrometry, chromatography

\section{INTRODUCTION}

Worldwide overweight and obesity have become a major health threat. In 2016 more than 1.9 billion adults ( $\geq 18$ years old) presented overweight, from which 650 million were obese ${ }^{1}$. Both conditions are one of the major risk factor for several diseases like diabetes type 2 and cardiovascular diseases. These diseases area classified as chronic non-communicable diseases (CNCD), which are pathologies characterized for showing long duration and slow progression. The main CNCD risk factors are tobacco use, physical inactivity, harmful use of alcohol and unhealthy diets. Regarding the latter, it has been clearly established the relation between health and diet. Since CNCD incidence has continuously increase, a new kind of food has been developed/elaborated called functional foods. A simple definition describes the functional foods as processed or unprocessed foods that contain biologically active components that exert healthy effects beyond of intrinsic nutritional effect, that may reduce the risk of suffer from $\mathrm{CNCD}{ }^{2}$. In this regard, chili peppers could be classified as a functional food considering the healthy effects ascribed to its consumption. Chili peppers are fruits from the genus Capsicum and belong to the family Solanaceae. The genus Capsicum L. comprises five main species: C. annuum, C. frutescens, $C$. chinense, C. baccatum and C. pubescens. These peppers varieties are worldwide used and valued for their sensory properties, i.e. color, pungency and aroma.
Pungency, a commercially important attribute of peppers, is produced by particular group of molecules denominated capsaicinoids ${ }^{3}$. Capsaicin and dihydrocapsaicin are the two most abundant capsaicinoids in chili peppers, constituting about $90 \%{ }^{4-6}$. Other minor ones are nordihydrocapsaicin, norcapsaicin, homocapsaicin, nornorcapsaicin, nornornorcapsaicin and nonivamide ${ }^{7-9}$. Capsaicinoids content depend on the genotype and maturation stage ${ }^{10}$. Capsaicin and other capsaicinoids produce a number of physiological and pharmacological effects on the cardiovascular system ${ }^{11}$ and gastrointestinal tract ${ }^{12}$. Capsaicin has been used in neurological research to stimulate sensory nerves and also to treat bladder inflammation. In topical ointments has been used for arthritis and neuralgia treatment ${ }^{13}$. Regarding its consumption, in Latin America, Mexico is the country with highest intake of Capsicum spices corresponding to $20 \mathrm{~g}$ per day ${ }^{14}$ (equivalent to one chili pepper) ${ }^{15}$. In USA and Europe the maximum daily intake of capsaicin from mild chilies and paprika is about $1.5 \mathrm{mg}$ per day ${ }^{16}$. According to a recent estimation, the mean and maximum intakes of capsaicin from industrially prepared food products that contains the recommended general limit of $5 \mu \mathrm{g} \mathrm{g}^{-1}$ is 0.77 and $2.64 \mathrm{mg}$ per day, respectively ${ }^{14,17}$. The pungency level has been evaluated using the Scoville Organoleptic Test ${ }^{18}$, which express the pungency level in a scale called the Scoville Heat Unit (SHU) ${ }^{18}$. Today this test has since been replaced by instrumental methods that measure the capsaicinoids (capsaicin) content in chili 
peppers, e.g. gas chromatography (GC) ${ }^{19}$, liquid chromatography (HPLC) ${ }^{20}$, and thin layer chromatography (TLC) ${ }^{21}$, among others. By far the most common technique used for the determination and quantification of this type of compound is reversed phase HPLC due to its reliability. Several extraction methods has been described for capsaicinoids extraction from chili peppers, i.e. solid-liquid extraction ${ }^{22}$, ultrasound-assisted extraction ${ }^{23}$, microwave ${ }^{7}$ and pressurized liquid extraction ${ }^{24}$. Due to its functional properties, it is relevant to determine the capsaicin and dihydrocapsaicin content in chili peppers commonly consumed by the population. For this reason, the objective of this work was to optimize and validate a liquid chromatographic method with fluorescence and mass spectrometry detection for capsaicin and dihydrocapsaicin determination in chili peppers. To the best our knowledge this is the first report about capsaicin determination in chili peppers commercialized in Chile.

\section{MATERIAL AND METHODS}

\subsection{Reagents, chemicals and samples}

Capsaicin [8-metil-N-vanillyl-trans-6-nonenamide, MW $305.41 \mathrm{~g} \mathrm{~mol}^{-1}$ $\geq 95 \%$ ] was purchased from Sigma (St. Louis, MO, USA). LC-grade methanol $(\mathrm{MeOH})$ and acetonitrile $(\mathrm{ACN})$ and acetic acid $(99.8 \%)$ were obtained from Merck (Darmstadt, Germany). Ultrapure water $(18.2 \mathrm{M} \Omega \mathrm{cm})$ was produced by means of Simplicity system from Millipore (Bedford, MA, USA). Filter paper $\mathrm{N}^{\circ} 4$ was obtained from Whatman (NJ, USA) and $13 \mathrm{~mm}$ PVDF syringe filters $(0.45 \mu \mathrm{m}$ pore size) were purchased from Millipore. Capsaicin stock solution was prepared in mobile phase (MeOH : ACN : acetic acid; 50:50:0.1 v/v/v) for a given concentration of $10 \mathrm{mg} \mathrm{L}^{-1}$. Working solutions were prepared by aliquot from stock solutions. All the solutions kept refrigerated at $4^{\circ} \mathrm{C}$ were stable for at least seven days. Twelve different chili peppers samples from three Capsicum species were purchased in local market and supermarket. Cultivated varieties (cv.) "square green pepper", "Camuyo", "Sweet banana" and green and mature "Cacho de cabra" from C. annum and "green chili", "Anaheim", "Hungarian", "Cristal", "Escabeche" and "Cayena" from C. baccatum var Pendulum and "Putamadre" from C. chacoense, were analyzed.

\subsection{Sample preparation}

First peduncle and seeds were separated, then, the rest of the chili pepper was homogenized using mortar and pestle. Capsaicinoids were extracted from homogenized samples applying the method described by Collins et al. ${ }^{25}$ with slight modifications. Briefly, $120 \mathrm{~mL}$ of methanol were added to $12 \mathrm{~g}$ of sample, the extraction was carried out by shaking in a KS 125 basic shaker from IKA (Staufen, Germany) at $150 \mathrm{rpm}$ for 4 hours at $40^{\circ} \mathrm{C}$. The extract was filtered through filter paper $\mathrm{N}^{\circ} 4$ and $10 \mathrm{~mL}$ of filtrated evaporated to dryness with a gently nitrogen stream at $60^{\circ} \mathrm{C}$. The residue was dissolved with $4 \mathrm{~mL}$ of organic mobile phase $(\mathrm{MeOH}: \mathrm{ACN}$ : acetic acid (50:50:0.1 v/v/v) and subjected to a series of dilutions according to the observed concentration. Standard solutions and samples were filtered through a $13 \mathrm{~mm}$ PVDF syringe filter $(0.45 \mu \mathrm{m})$ before HPLC injection.

\subsection{Chromatography}

Capsaicinoids analysis was carried out using a Shimadzu (Kyoto, Japan) Prominence HPLC system, composed by: LC-20AT binary pump, DGU-20A5R degassing unit, SIL-20AC autosampler, CBM-20A communication module, CTO-20AC column oven and RF-20A fluorescence detector, all controlled by means of LabSolutions software (version 5.51). Chromatography was performed on Agilent Zorbax Eclipse XDB-C ${ }_{18}(4.6 \times 150 \mathrm{~mm} ; 3.5 \mu \mathrm{m})$ column connected to guard-column of the same chemistry, both set at $40^{\circ} \mathrm{C}$. A binary mobile phase composed acidified water $(0.1 \% \mathrm{v} / \mathrm{v}$ acetic acid, solvent $\mathrm{A})$ and a mixture of $\mathrm{MeOH}: \mathrm{ACN}$ : acetic acid (50:50:0.1 v/v/v solvent B), was used applying the following gradient program at a flow rate of $0.8 \mathrm{~mL} \mathrm{~min}^{-1}$ : $0-5 \mathrm{~min} 60-60 \%$ B, $5-9 \min 60-90 \%$ B, $9-11 \min 90-90 \%$ B, $11-15 \min 90-60 \%$ B, $15-25$ min $60-60 \%$ B (column conditioning). Detection was performed by fluorescence using 280 and $320 \mathrm{~nm}$ as excitation and emission wavelengths, respectively. Peak identity confirmation was carried out by mass spectrometry using a Shimadzu LCMS-8030 triple quadrupole system. Molecules ionization was done by electrospray ionization ${ }^{14}$ operated in positive mode with a capillary voltage of $4.5 \mathrm{kV}$; desolvation line temperature of $250^{\circ} \mathrm{C}$, heat block temperature of $400^{\circ} \mathrm{C}$, nebulizing gas $\left(\mathrm{N}_{2}\right) 3.0 \mathrm{~L} \mathrm{~min}^{-1}$ and drying gas $\left(\mathrm{N}_{2}\right) 15.0 \mathrm{~L} \mathrm{~min}{ }^{-1} . \mathrm{m} / z$ detection was performed in scan mode.

\subsection{Scoville Heat Unit (SHU)}

Scoville heat unit of samples was calculated applying the method proposed by Todd et al ${ }^{26}$. The method is based in multiplying the capsaicin concentration by the individual dilution factor $\left(1.6 \times 10^{7}\right)$ that causes burning sensation.

\subsection{Statistical Analysis}

Data were evaluated using descriptive statistics [mean, standard deviation (SD) and the relative standard deviation (RSD)]. Calibration equation was established applying a linear regression model relating capsaicin concentrations $\left(\mathrm{mg} \mathrm{L}^{-1}\right)$ and peak area signals. Dihydrocapsaicin was quantified using capsaicin calibration. Calibrations with and without matrix were compared using F-test. All statistical tests were performed with a significance level $(\alpha)$ of 0.05 using GraphPad (San Diego, CA, USA) Prism 6.0 software. Central Composite Design (CCD), which was prepared and analyzed by means of program Statgraphics Centurion XV software version 15.1.02 (Rockville, MD, USA).

\section{RESULTS AND DISCUSSION}

\subsection{Chromatographic optimization}

Due to its high efficiency with a reduced number of experiments, a facecentered central composite design with two central points was selected to optimize the chromatographic parameters 27 . Two capsaicin responses were defined as critical to achieve an adequate and reliable quantification, i.e. peak height and resolution. The first one with the purpose of enhancing detection limit and the second one to obtain a clear separation between capsaicin and nordihydrocapsaicin peaks from matrix. Considering these responses, optimization was focused in two factors, slope of organic solvent in the mobile phase $\left(\mathrm{X}_{1}\right)$, expressed as the percentage of organic solvent at 9 min of gradient program and column temperature $\left(\mathrm{X}_{2}\right)$. According to preliminary chromatographic assays, a range was established for organic mobile phase percentage at $9 \mathrm{~min}(70-100 \% \mathrm{v} / \mathrm{v})$ and column temperature $\left(35-55^{\circ} \mathrm{C}\right)$, which resulted in an experimental plan with 10 runs (Table 1). All experiments were randomly conducted in triplicate $(n=3)$ in order to minimize the effects of uncontrolled factors. Experimental data from peak height response and resolution fitted a second-degree model with a cubic experimental domain. An analysis of variance (ANOVA) with a significance level of 0.05 was carried out to determine which experimental factors significantly affect the chromatographic performance regarding peak height and resolution.

Table 1. Experimental runs for a central composite design with the corresponding responses (means) for resolution and peak height.

\begin{tabular}{|c|c|c|c|c|}
\hline \multirow{2}{*}{ Experiments (Runs) } & \multicolumn{2}{|r|}{ Factors } & \multicolumn{2}{|c|}{ Responses* } \\
\hline & Temperature $\left({ }^{\circ} \mathrm{C}\right)$ & MeOH:ACN:acetic acid (50:50:0.1 v/v/v) & Resolution & Peak Height $(\mathbf{E U})^{\mathrm{a}}$ \\
\hline 1 & 45 & 85 & $0.80 \pm 0.01$ & $766283 \pm 3.53$ \\
\hline 2 & 45 & 100 & $0.74 \pm 0.02$ & $534627 \pm 5.65$ \\
\hline 3 & 55 & 70 & $0.50 \pm 0.04$ & $489252 \pm 4.24$ \\
\hline 4 & 35 & 85 & $0.47 \pm 0.03$ & $929672 \pm 4.94$ \\
\hline 5 & 45 & 70 & $0.80 \pm 0.07$ & $538878 \pm 2.12$ \\
\hline 6 & 45 & 85 & $0.65 \pm 0.04$ & $885623 \pm 7.77$ \\
\hline 7 & 35 & 100 & $0.72 \pm 0.07$ & $673380 \pm 12.02$ \\
\hline 8 & 55 & 85 & $0.74 \pm 0.03$ & $568568 \pm 7.07$ \\
\hline 9 & 35 & 70 & $1.10 \pm 0.23$ & $549022 \pm 2.82$ \\
\hline 10 & 55 & 100 & $0.77 \pm 0.02$ & $539048 \pm 4.24$ \\
\hline
\end{tabular}

${ }^{a}$ Emission units

${ }^{*}$ mean \pm standard deviation $(n=3)$. 
According to the observed results, none of the factors significantly $(\mathrm{P}>0.05)$ influenced the variables response. The quadratic coefficient of percentage of $\mathrm{MeOH}: \mathrm{ACN}$ to 9 min gradient mobile phase affected significantly the peak height $(\mathrm{P}<0.05)$. This result has not implications from the standpoint of the analytical method. Using the individual optimum, a multiple response optimization was done in order to determine the optimal conditions for all responses, giving desirability conditions. Thus, the optimal conditions calculated were: $76 \%$ organic mobile phase at 9 min of gradient program and column temperature of $35^{\circ} \mathrm{C}$, with these chromatographic conditions clear and well-resolved chromatograms were obtained (Fig 1).

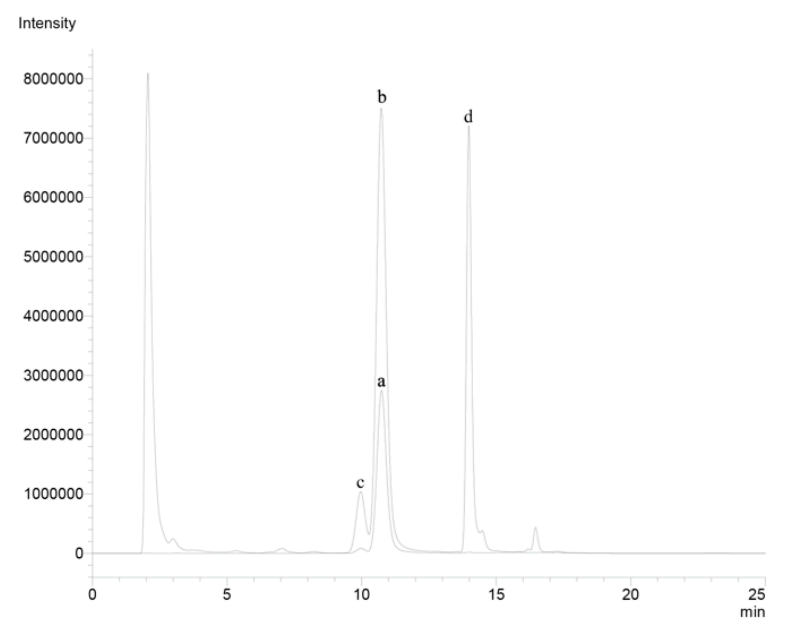

Fig 1. Chromatogram capsaicin standard of $1 \mathrm{mg} \mathrm{L}^{-1}$ and extract of green pepper spiked with $1 \mathrm{mg} \mathrm{L}^{-1}$ of capsaicin standard in optimal conditions.

\subsection{Validation}

Validation of method was to carried out according to ICH recommendations ${ }^{28}$. Calibrations with and without matrix were compared in order to evaluate a possible matrix effect. No statistical difference was observed among slopes $(\mathrm{F}=0.008, \mathrm{P}=0.92)$; hence, calibration was established with pure standard in the range of 0.01 to $2.00 \mathrm{mg} \mathrm{L}^{-1}$ with six levels in triplicate. Calibration data fitted a linear regression model with a determination coefficient $\left(R^{2}\right)$ of 0.998 (Table 2). Method precision was evaluated through repeatability and intermediate precision. Repeatability was studied injecting in sextuplicate $(n=6)$ a $0.5 \mathrm{mg} \mathrm{L}^{-1}$ Capsaicin standard showing a RSD of $1.51 \%$. Intermediate precision was established measuring in triplicate $(n=3)$ a $0.5 \mathrm{mg} \mathrm{L}^{-1}$ capsaicin standard during three days $(n=3)$, showing a RSD of $1.04 \%$. Method accuracy was determined through recovery evaluation. Chili pepper samples were spiked with three capsaicin concentration levels, i.e. $0.01,0.50$ and $2.00 \mathrm{mg} \mathrm{L}^{-1}$, defined according to the calibration range and the reported values. Each level was prepared daily and measured in duplicate during three days. Recovery in all matrices was adequate with values ranging from 94.80 to $109.40 \%$ with RSD lower than $2.39 \%$. Detection and quantification limits were calculated using signal-to-noise ratios $(\mathrm{S} / \mathrm{N})$ of 3 and 10, respectively. Considering an injection volume of $20 \mu \mathrm{L}$, the detection and quantification limits in chili peppers were 0.003 and $0.010 \mathrm{mg} \mathrm{L}^{-1}$, respectively. Robustness was evaluated simultaneously with optimization using a response surface design. According to ANOVA results the proposed chromatographic method is robust for the percentage of organic solvent at 9 min of gradient program and column temperature $(\mathrm{P}>0.05)$. ICH describes the term specificity, but due to the general agreement and the IUPAC recommendation ${ }^{29}$, the preferred and promoted term is selectivity.

Capsaicin identification was established by retention time ${ }^{30}$ comparison with pure standard and using the standard addition method. Selectivity was studied by mass spectrometry. Each chromatographic peak showed only one protonated molecule corresponding to each capsaicinoids evaluated finding $\mathrm{m} / \mathrm{z}$ 294 for nordihydrocapsaicin, $m / \mathrm{z} 306$ for capsaicin and $\mathrm{m} / \mathrm{z} 308$ for dihydrocapsaicin (Fig 2), which are in agree with the values already described in literature ${ }^{31}$.

Comparatively, this optimized method showed similar validation results than others methods for capsaicinoides determination in peppers using liquid chromatography. Detection and quantification limits were much lower than those reported by Stipcovich et al ${ }^{32}$ using UHPLC/MS method (LOD $0.1 \mathrm{mg} \mathrm{L}^{-1}$; LOQ $\left.0.3 \mathrm{mg} \mathrm{L}^{-1}\right)$. Linear range $\left(0.01\right.$ to $\left.2.00 \mathrm{mg} \mathrm{L}^{-1}\right)$ is lower than reported by Sganzerla et al ${ }^{5}\left(0.0055-66 \mathrm{mg} \mathrm{L}^{-1}\right)$ and Cisneros-Pineda ${ }^{30}\left(0.25-2.50 \mathrm{mg} \mathrm{mL}^{-}\right.$ $\left.{ }^{1}\right)$. Recovery results $(>90 \%)$ are similar to those reported by Sganzerla et al ${ }^{5}(88$ to $112 \%)$, and Sweat et al ${ }^{33}$ (101 to $\left.115 \%\right)$. In terms of precision showing RSD value the $1.04 \%$ lower than reported by Sganzerla et al ${ }^{5}(6.11 \%)$ and Sweat et al ${ }^{33}(6.9 \%)$.

Table 2. Summary of validation results of analytical method applied to evaluated capsaicin in chile peppers

\begin{tabular}{|c|c|c|c|c|c|c|c|c|c|}
\hline $\begin{array}{l}\text { Range }^{\mathrm{a}} \\
\left(\mathrm{mg} \mathrm{L} \mathbf{L}^{-1}\right)\end{array}$ & $\begin{array}{c}\text { Regression equation }^{b} \\
\mathbf{y}=\mathbf{a x} \pm \mathbf{S D}+\mathbf{b} \pm \mathbf{S D}\end{array}$ & $\mathbf{R}^{2}$ & \multicolumn{2}{|c|}{$\begin{array}{l}\text { Confidence interval } \\
\text { a }\end{array}$} & $\begin{array}{c}\mathbf{R p}^{\mathbf{c}} \\
(\% \mathbf{R S D})\end{array}$ & $\begin{array}{c}\text { IP }^{\mathrm{d}} \\
(\% \mathrm{RSD})\end{array}$ & $\begin{array}{l}\text { Recoverye } \\
\text { (\%) }\end{array}$ & $\begin{array}{c}\operatorname{LOD}^{f} \\
\left(\operatorname{mg~L}^{-1}\right)\end{array}$ & $\begin{array}{c}\mathrm{LOQ}^{\mathrm{g}} \\
\left(\mathrm{mg} \mathrm{L}^{-1}\right)\end{array}$ \\
\hline $0.01-2.00$ & $y=4987.70 x \pm 46.86+102.81 \pm 52.43$ & 0.998 & $\begin{array}{c}4888 \pm \\
5087\end{array}$ & $-8.34 \pm 214.0$ & 1.51 & 1.04 & $\begin{array}{l}94.85 \pm 2.39- \\
108.48 \pm 1.04\end{array}$ & 0.003 & 0.01 \\
\hline
\end{tabular}

${ }^{a}$ range: 0.01 to $2 \mathrm{mg} \mathrm{L}^{-1} . \quad{ }^{\mathrm{b}} n=3$ three injections $\quad{ }^{\mathrm{c}} \mathrm{Rp}$ : repeatability, $n=6 \quad{ }^{\mathrm{d}} \mathrm{IP}$ : intermediate precision, $n=3 \quad{ }^{\mathrm{e}}$ mean $\pm \mathrm{SD}, n=3 \quad{ }^{\mathrm{f}} \mathrm{S} / \mathrm{N}=3 \quad{ }^{\mathrm{g}} \mathrm{S} / \mathrm{N}=10$ for each level
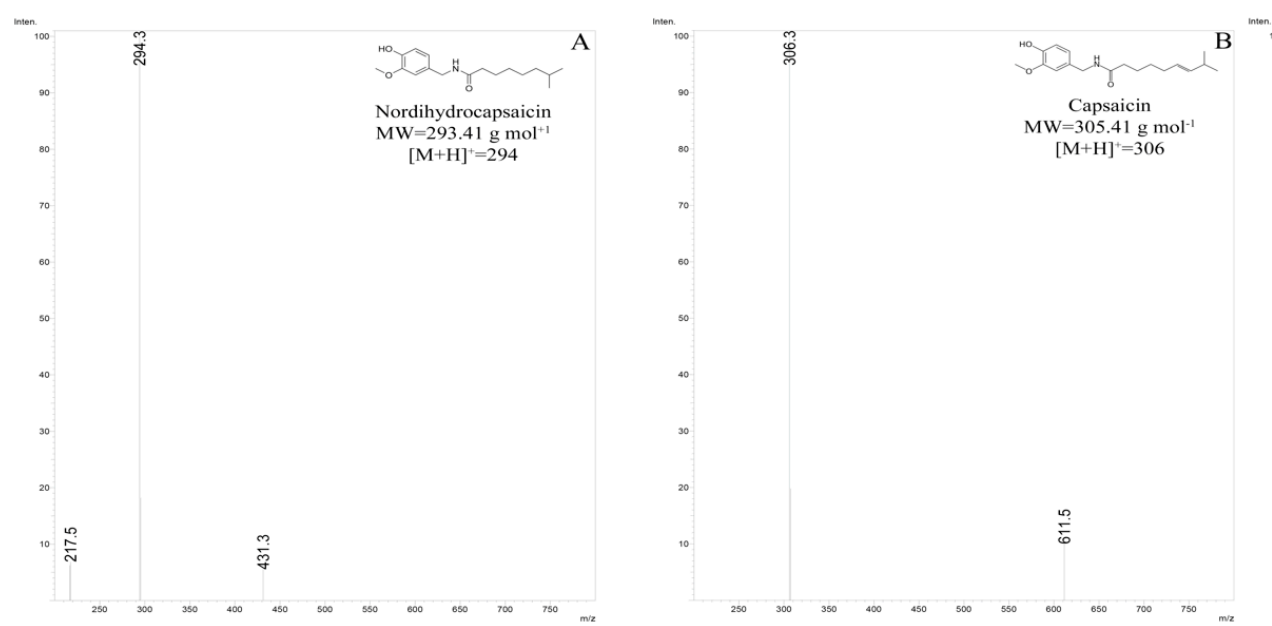

Fig 2. Mass spectrum of nordihydrocapsaicin (A), capsaicin (B) and dihydrocapsaicin (C). 


\subsection{Samples analysis}

Twelve samples were analyzed using the optimized and validated method. The analytical method developed permitted the separation of 3 capsaicinoids in 15 min run. Since no commercially available dihydrocapsaicin standard was found, both, capsaicin and dihydrocapsaicin contents were quantified using capsaicin calibration. For the case of nordihydrocapsaicin it was not possible to quantified using capsaicin calibration because the levels found were below calibration range. Samples showed a capsaicin content from 0.10 to $127.30 \mathrm{mg}$ $\mathrm{kg}^{-1}$ and dihydrocapsaicin from 1.46 to $100.20 \mathrm{mg} \mathrm{kg}^{-1}$ (Table 3). The corresponding capsaicin contents were converted to Scoville heat units in order to classify them according to their pungency levels (Table 3). The use of the SHU parameter is the recommended method for pepper evaluation as it provides a better indicator of the pungency level, but is considered less precise ${ }^{5}$. Capsicum cv. Pimiento cuadrado verde, Sweet banana, Anaheim, Hungaro, Cristal and Escabeche presented the lowest capsaicinoids content and, therefore, the lowest pungency. Instead, cv. Cacho de cabra, showed the highest capsaicin content and, therefore, the highest pungent level. Since this is the first report about capsaicin content in chili peppers commercialized in Chile it was not possible to compare or discuss the values found. However, these results are in agree with those reported by Othman et al ${ }^{34}$ for the same capsicum species. Regarding the maturity effect over capsaicinoids content, Capsicum cv. Cacho de cabra showed the typical behavior observed during ripening ${ }^{35}$. Capsaicin and dihydrocapsaicin content decreases according to the ripeness of the fruit, increasing the content of other capsaicinoids. In the same way some harvest period also influences capsaicin concentration ${ }^{35}$.

The contents of capsaicin and dihydrocapsaicin found in the present work (2 to $127 \mu \mathrm{g} \mathrm{g}^{-1}$ and 1.5 to $100 \mu \mathrm{g} \mathrm{g}^{-1}$ respectively) for the different pepper varieties are in good agreement with those found by other authors who reported that a variation in capsaicin concentration is observed in the different peppers ${ }^{25}$. Sganzerla ${ }^{5}$ found that levels for capsaicin to $156-1442 \mu \mathrm{g} \mathrm{g}^{-1}$ and for dihydrocapsaicin 26-478 $\mu \mathrm{g} \mathrm{g}^{-1}$. Duelund et al ${ }^{36}$ found ranges to $0.69-131 \mu$ mole $\mathrm{g}^{-1}$ for capsaicin and 0.66 to $28.35 \mu$ mole $\mathrm{g}^{-1}$ for dihydrocapsaicin. Stipcovich et al $^{32}$ in 7 samples of hot peppers found concentrations for capsaicin 274-4469 $\mu \mathrm{g}$ $\mathrm{g}^{-1}$ and for dihydrocapsaicin $120-2319 \mu \mathrm{g} \mathrm{g}^{-1}$.

Table 3. Capsaicinoids content $\left(\mu \mathrm{g} \mathrm{g}^{-1}\right)$ in Chilean peppers.

\begin{tabular}{|c|c|c|c|c|c|}
\hline Sample & Chili & $\begin{array}{l}\text { Capsaicin content } \\
\quad\left(\mu \mathrm{g} \mathrm{g}^{-1} \pm \mathrm{SD}\right)\end{array}$ & $\begin{array}{c}\text { Dihydrocapsaicin content } \\
\qquad\left(\mu \mathrm{g} \mathrm{g}^{-1} \pm \mathrm{SD}\right)\end{array}$ & SHU & Pungency level \\
\hline 1 & Square green pepper (Capsicum annum) & $2.00 \pm 0.41$ & $2.80 \pm 0.27$ & $320.00 \pm 47.37$ & No pungent \\
\hline 2 & Camuyo (Capsicum annum) & $6.83 \pm 2.49$ & $6.30 \pm 0.31$ & $1092.80 \pm 71.15$ & Midly pungent \\
\hline 3 & Sweet banana (Capsicum annum) & $12.20 \pm 3.18$ & $9.38 \pm 0.18$ & $195.20 \pm 31.96$ & No pungent \\
\hline 4 & Puta madre (Capsicum chacoense) & $43.26 \pm 14.30$ & $24.12 \pm 0.33$ & $692.16 \pm 69.67$ & Midly pungent \\
\hline 5 & Green chili (Capsicum pendulum) & $14.31 \pm 0.00$ & $7.07 \pm 3.05$ & $2289.60 \pm 63.82$ & Midly pungent \\
\hline 6 & Anaheim (Capsicum pendulum) & $0.30 \pm 1.85$ & $3.77 \pm 3.31$ & $48.00 \pm 21.21$ & No pungent \\
\hline 7 & Hungarian (Capsicum pendulum) & $0.10 \pm 0.21$ & $1.46 \pm 0.30$ & $16.00 \pm 55.15$ & No pungent \\
\hline 8 & Green Cacho de cabra (Capsicum annum) & $127.30 \pm 1.20$ & $100.24 \pm 9.04$ & $20368.00 \pm 19.09$ & Highly pungent \\
\hline 9 & Mature Cacho cabra (Capsicum annum) & $15.65 \pm 2.03$ & $7.47 \pm 2.05$ & $2504.00 \pm 77.78$ & Midly pungent \\
\hline 10 & Cristal (Capsicum pendulum) & $1.10 \pm 0.31$ & $1.81 \pm 0.48$ & $160.00 \pm 21.92$ & No pungent \\
\hline 11 & Cayena (Capsicum pendulum) & $12.07 \pm 6.48$ & $20.13 \pm 4.51$ & $1931.20 \pm 17.53$ & Midly pungent \\
\hline 12 & Escabeche (Capsicum pendulum) & $33.51 \pm 62.50$ & $30.47 \pm 60.70$ & $536.16 \pm 36.65$ & No pungent \\
\hline
\end{tabular}

\section{CONCLUSIONS}

This work report an optimized and validated method for a reliable quantification of capsaicinoids in peppers. The optimization via central composite design of the chromatographic conditions allowed a well-resolved separation of three capsaicinoids in $25 \mathrm{~min}$ without matrix interferences. Considering validation results the method proved to be reliable, accurate and precise. To the best of our knowledge, this study shows for the first time the evaluation of capsaicinoids in peppers commercialized in Chilean market. All 12 chili pepper samples analyzed showed the presence of nordihydrocapsaicin, capsaicin, and dihydrocapsaicin, which were the main capsaicinoids in the different chili and pepper samples. The variety "Cacho de cabra" green was the one with the major pungency. Variations in capsaicinoids quantity could be attributed to genetic factors to each cultivar or alternatively to the environmental conditions where they were cultivated.

\section{ACKNOWLEDGEMENTS}

This work is part of Jessy Pavón-Pérez thesis to obtain the degree of Doctor in Science and Analytical Technology from the University of Concepcion, Chile. The authors want to thank to the National Commission of Scientific and Technological Research (CONICYT) of the Chilean Government for the doctoral scholarship granted $\mathrm{N}^{\mathrm{0}} 63140062$. This work was financially supported by National Fund for Scientific \& Technological Development (FONDECYT), project $N^{\circ} 1171857$, FONDEQUIP 130209 and the University of Concepcion.
1. World Health Organization (WHO), Obesity and overweight. (2018) acces date: February 21, 2018

2. A. Stein, E. Rodríguez-Cerezo, Functional food in the European Union. Joint Research Centre. European Commission. (2008).

3. I. Perucka, M. Materska, Innov Food Sci Emerg 2, 189, (2001).

4. A. Topuz, F. Ozdemir, J Food Compost Anal 20, 596, (2007).

5. M. Sganzerla, J.P. Coutinho, A.M.T. de Melo, H.T. Godoy, Food Res Int 64, 718, (2014).

6. A. Morales-Soto, A.M. Gómez-Caravaca, P. García-Salas, A. SeguraCarretero, A. Fernández-Gutiérrez, Food Res Int 51, 977, (2013).

7. G.F. Barbero, M. Palma, C.G. Barroso, Anal Chim Acta 578, 227, (2006).

8. M.F. Sadayoshi Kosuge, Agr Biol Chem 34, 248, (1970).

9. R.L. Jarret, B. Perkins, T. Fan, A. Prince, K. Guthrie, B. Skoczenski, J Food Compost Ana 16, 189, (2003).

10. M.G. Usman, M.Y. Rafii, M.R. Ismail, M.A. Malek, M.A. Latif, Molecules 19, 6474, (2014).

11. E. Morales-Soriano, B. Kebede, R. Ugás, T. Grauwet, A. Van Loey, M. Hendrickx, Food Res Int 109, 250, (2018).

12. A. Schmidt, G. Fiechter, E.-M. Fritz, H.K. Mayer, J Food Compost Ana 60, 32, (2017).

13. M.M. Backonja, Eur J Pain 4, 170, (2010).

14. E. Becerra-Martínez, E. Florentino-Ramos, N. Pérez-Hernández, L. Gerardo Zepeda-Vallejo, N. Villa-Ruano, M. Velázquez-Ponce, F. García-Mendoza, A.E. Bañuelos-Hernández, Food Res Int 102, 163, (2017). 
15. L. Lopez-Carrillo, M. Hernandez Avila, R. Dubrow, Am J Epidemiol 139, 263, (1994).

16. V.S. Govindarajan, U.J. Salzer, Crit Rev Food Sci 23, 207, (1986).

17. E.C.H.C. Protection, Opinion of the Scientific Committee on Food on Capsaicin. (2002).

18. W.L. Scoville., J Am Pharm Assoc 1, 453, (1912).

19. A.M. Krajewska, J.J. Powers, J Chromatogr A 409, 223, (1987).

20. O. Monago-Maraña, M. Guzmán-Becerra, A. Muñoz de la Peña, T. GaleanoDíaz, J Food Compost Anal 67, 10, (2018)

21. P.K.S. Bhuvaneshwari S, Alice Kuruvilla, Int. j. pharm. biol. sci. arch 4, (2013).

22. W.-K. Ryu, H.-W. Kim, G.-D. Kim, H.-I. Rhee, J Food Drug Anal 25, 798, (2017).

23. G.F. Barbero, A. Liazid, M. Palma, C.G. Barroso, Talanta 75, 1332, (2008).

24. T. Bajer, P. Bajerová, D. Kremr, A. Eisner, K. Ventura, J Food Compost Anal 40, 32, (2015).

25. M.D. Collins, L.M. Wasmund, P.W. Bosland, HortScience 30, 137, (1995).

26. P.H. Todd, M.G. Bensinger, T. Biftu, J Food Sci 42, 660, (1977).

27. S.L.C. Ferreira, R.E. Bruns, E.G.P. da Silva, W.N.L. dos Santos, C.M. Quintella, J.M. David, J.B. de Andrade, M.C. Breitkreitz, I.C.S.F. Jardim, B.B. Neto, J. Chromatogr. A 1158, 2, (2007).
28. I.C.o.H. (ICH), 2005.

29. R.I.S. Jörgen Vessman, Jacobus F. van Staden, Klaus Danzer, Wolfgang Lindner, Duncan Thorburn Burns, Aleš Fajgelj, Helmut Müller, Pure Appl. Chem 73, 1381, (2001).

30. O. Cisneros-Pineda, L.W. Torres-Tapia, L.C. Gutiérrez-Pacheco, F. Contreras-Martín, T. González-Estrada, S.R. Peraza-Sánchez, Food Chem 104, 1755, (2007).

31. A. Peña-Alvarez, L.A. Alvarado, L.E. Vera-Avila, Instrum Sci. Technol. 40, 429, (2012).

32. T. Stipcovich, G.F. Barbero, M. Ferreiro-González, M. Palma, C.G. Barroso, Food Chem 239, 217, (2018).

33. K.G. Sweat, J. Broatch, C. Borror, K. Hagan, T.M. Cahill, Food Chem 210, 606, (2016).

34. Z.A.A. Othman, Y.B.H. Ahmed, M.A. Habila, A.A. Ghafar, Molecules 16, 8919, (2011).

35. G.F. Barbero, A.G. Ruiz, A. Liazid, M. Palma, J.C. Vera, C.G. Barroso, Food chem 153, 200, (2014).

36. L. Duelund, O.G. Mouritsen, Food Chem 221, 913, (2017). 